\title{
Pertumbuhan dan Produksi Tanaman Tempuyung (Sonchus arvensis L.) dengan Komposisi Media Tanam yang Berbeda
}

\author{
Growth dan Production of Sowthistle (Sonchus arvensis L.) in Different Media \\ Composition
}

Denti Dewi Gatari ${ }^{1^{*}}$ dan Maya Melati ${ }^{1}$

Diterima 15 November 2013/Disetujui 14 Januari 2014

\begin{abstract}
Sowthistle is one of wild medicinal plants. Sowthistle can be planted in the pot, polybag or land with mix of organic material or sand with lime. The objective of this research was to determine the effect of media composition on the growth and production of sowthistle (Sonchus arvensis $\mathrm{L}$.). The experiment was arranged in a randomized complete block design with one factor, three treatments and three replications. The treatments were $8 \mathrm{~kg}$ soil, $7.5 \mathrm{~kg}$ soil $+0.5 \mathrm{~kg}$ cow manure, 7 $\mathrm{kg}$ soil $+0.5 \mathrm{~kg}$ cow manure $+0.5 \mathrm{~kg}$ rice hull charcoal polybag ${ }^{-1}$. The three treatments used lime with the rate of $10 \mathrm{~g} \mathrm{polybag}^{-1}$. Media composition as control was $7 \mathrm{~kg}$ soil $+0.5 \mathrm{~kg}$ cow manure + $0.5 \mathrm{~kg}$ rice hull charcoal without lime. Every treatment consisted of 10 plants. The results of experiment showed that unaffected by composition did not the growth and yield component of sowthistle media. Compared to treatment without lime, fresh weight of root at 5 MST with the application of cow manure was significantly smaller.
\end{abstract}

Keywords: cow manure, lime, rice hull charcoal

\begin{abstract}
ABSTRAK
Tempuyung merupakan salah satu tanaman obat yang tumbuh liar. Budi daya tempuyung dapat dilakukan di dalam pot, polybag, atau lahan dengan menggunakan bahan organik yang dicampur dengan puing bangunan atau pasir serta batu yang diberi banyak kapur. Penelitian ini dilakukan untuk mengetahui pengaruh komposisi media tanam terhadap pertumbuhan dan produksi tanaman tempuyung (Sonchus arvensis L.). Percobaan ini menggunakan rancangan kelompok lengkap teracak (RKLT) faktor tunggal, tiga taraf dan tiga perlakuan yaitu $8 \mathrm{~kg}$ tanah, $7.5 \mathrm{~kg}$ tanah + $0.5 \mathrm{~kg}$ pupuk kandang sapi, $7 \mathrm{~kg}$ tanah $+0.5 \mathrm{~kg}$ pupuk kandang sapi $+0.5 \mathrm{~kg}$ arang sekam polybag ${ }^{-1}$. Ketiga perlakuan menggunakan dosis kapur $10 \mathrm{~g}_{\text {polybag }}{ }^{-1}$. Komposisi media tanam sebagai pembanding adalah $7 \mathrm{~kg}$ tanah $+0.5 \mathrm{~kg}$ pupuk kandang sapi $+0.5 \mathrm{~kg}$ arang sekam tanpa kapur. Setiap perlakuan terdiri atas 10 tanaman dan diulang sebanyak tiga kali. Hasil penelitian menunjukkan bahwa komposisi media tanam tidak mempengaruhi peubah vegetatif dan komponen hasil tanaman tempuyung. Bobot basah akar pada umur 5 MST dengan penambahan pupuk kandang sapi nyata lebih kecil dibandingkan dengan perlakuan tanpa kapur.
\end{abstract}

Kata kunci: arang sekam, kapur, pupuk kandang sapi

\section{PENDAHULUAN}

Indonesia memiliki keanekaragaman hayati yang dapat dimanfaatkan dalam semua aspek kehidupan manusia. Tanaman obat digunakan oleh masyarakat sebagai salah satu alternatif pengobatan, baik untuk pencegahan penyakit (preventif), penyembuhan (kuratif), pemulihan kesehatan (rehabilitatif) serta peningkatan kesehatan (promotif) (Hernani dan

${ }^{1}$ Departemen Agronomi dan Hortikultura, Fakultas Pertanian, Institut Pertanian Bogor

J1. Meranti, Kampus IPB Darmaga, Bogor 16680, Indonesia

*Penulis untuk korespondensi: dentidewigatari@gmail.com 
Nudjanah, 2009). Tempuyung sebagai salah satu jenis tanaman obat potensial yang menggunakan bagian daunnya untuk pengobatan (Siswanto et al., 2004). Permintaan simplisia rata-rata sebesar $4789 \mathrm{~kg}$ pada tahun 1993. Dugaan permintaan simplisia rata-rata pada tahun 2000 sebesar $24404 \mathrm{~kg}$ (Muhammad et al., 1993). Permintaan daun pada tanaman ini cukup tinggi namun usaha budi daya tempuyung belum intensif untuk memenuhi permintaan tersebut.

Tempuyung tumbuh liar di tempat terbuka yang terkena sinar matahari atau sedikit terlindung dan pada tanah yang agak lembab, seperti pinggir parit, pinggir jalan, sela-sela batu, tebing dan tembok miring (Djauhariya dan Hernani, 2004; Dalimartha, 2005). Tanaman ini dapat tumbuh di media tanah. Penelitian Wahyuningsih (2005) menunjukkan bahwa media tanam yang digunakan dalam budi daya tempuyung adalah campuran tanah dan pupuk kandang dengan perbandingan 1:1 dan pupuk anorganik. Komposisi media tanam yang lain perlu dicari dengan mempertimbangkan lingkungan tumbuh tempuyung pada umumnya. Campuran media yang dapat digunakan adalah pupuk kandang atau arang sekam yang merupakan limbah pertanian.

Pupuk merupakan masukan yang penting dalam produksi tanaman (Harahap, 2005). Pupuk kandang adalah salah satu bahan untuk memperbaiki sifat kimia tanah terutama dapat meningkatkan ketersediaan unsur hara makro $(\mathrm{N}$, $\mathrm{P}, \mathrm{K}, \mathrm{Ca}, \mathrm{Mg}$, dan S) dan mikro (Fe, Zn, Mn, B, $\mathrm{Cu}$, dan Mo) (Chairani, 2006). Kualitas pupuk kandang sangat tergantung pada jenis ternak dan kualitas pakan (Hadid dan Laude, 2007). Arang sekam yang diberikan pada media tanam dapat memperbaiki pertumbuhan tanaman, menambah hara tanah dan memperbaiki sifatsifat tanah terutama sifat fisik. Hasil penelitian Saleh (2010) menunjukkan bahwa penggunaan arang sekam sebagai media tanam dapat meningkatkan ketersediaan $\mathrm{N}$ dan $\mathrm{K}_{2} \mathrm{O}$.

Budi daya tempuyung dapat dilakukan di dalam pot, polybag, atau lahan dengan menggunakan bahan organik yang dicampur dengan puing bangunan atau pasir. Kajian tentang komposisi media tanam untuk tempuyung masih terbatas. Penelitian ini mempelajari kesesuaian berbagai jenis komposisi media tanam untuk pertumbuhan tempuyung. Menurut Foragri (2011), media tanam tempuyung harus material yang basa. Lahan bekas reruntuhan bangunan yang memiliki banyak zat kapur sangat cocok untuk media tanam tempuyung. Oleh karena itu, sebagai tambahan kajian juga akan mempelajari pengaruh kapur dalam media.

\section{BAHAN DAN METODE}

Penelitian ini dilaksanakan pada bulan Februari sampai Mei 2013 di Kebun Percobaan Cikarawang IPB, Dramaga Bogor. Analisis tanah dilaksanakan di Laboratorium Departemen Tanah, Fakultas Pertanian, Institut Pertanian Bogor. Bahan tanaman yang digunakan adalah anakan tempuyung yang berumur \pm 4 minggu atau yang memiliki 1-2 daun. Bahan-bahan lainnya adalah tanah, pupuk kandang, arang sekam, kapur, paranet, amplop coklat, koran dan polybag berukuran $40 \mathrm{~cm}$ x $50 \mathrm{~cm}$. Alatalat yang digunakan adalah alat budi daya pertanian, timbangan analitik dan oven dengan pengaturan suhu $80^{\circ} \mathrm{C}$ selama 2 hari.

Percobaan ini menggunakan Rancangan Kelompok Lengkap Teracak (RKLT) faktor tunggal yang terdiri atas tiga taraf yaitu: $\mathrm{M} 1=$ $8 \mathrm{~kg}$ tanah + kapur $10 \mathrm{~g}$ polybag $^{-1} . \mathrm{M} 2=7.5$ $\mathrm{kg}$ tanah $+0.5 \mathrm{~kg}$ pupuk kandang sapi + kapur $10 \mathrm{~g}_{\text {polybag }}{ }^{-1} . \mathrm{M} 3=7 \mathrm{~kg}$ tanah $+0.5 \mathrm{~kg}$ pupuk kandang sapi $+0.5 \mathrm{~kg}$ arang sekam + kapur $10 \mathrm{~g}$ polybag ${ }^{-1}$. Sebagai pembanding adalah $=7 \mathrm{~kg}$ tanah $+0.5 \mathrm{~kg}$ pupuk kandang sapi $+0.5 \mathrm{~kg}$ arang sekam.

Setiap perlakuan terdiri atas 10 tanaman dengan 3 ulangan, sehingga total tanaman ada 120 tanaman. Data pengamatan yang diperoleh dianalisis menggunakan sidik ragam (uji $\mathrm{F}$ ) taraf 5\%. Hasil pengamatan yang berbeda nyata diuji lanjut dengan Duncan Multiple Range Test (DMRT) taraf 5\% sedangkan untuk membandingkan dengan perlakuan tanpa kapur menggunakan uji lanjut t-dunnett. Data diolah menggunakan software SAS.

Percobaan diawali dengan persiapan lahan dan media tanam. Media tanam dipersiapkan 1 minggu sebelum tanam. Tanah diayak terlebih dahulu agar akar tanaman mudah menembus tanah dan aerasi tanah baik. Setiap polybag berisi media tanam yang berbeda sesuai dengan perlakuan. Bobot media per polybag sebesar $8 \mathrm{~kg}$. Anakan tempuyung yang digunakan telah berumur 4 minggu atau yang sudah memiliki 2 daun dipindahkan ke dalam poybag yang sudah dipersiapkan terlebih dahulu. Kapur diberikan secara melingkar dengan dosis $10 \mathrm{~g} \mathrm{polybag}^{-1}$. Jarak tanam antar 
polybag adalah $50 \mathrm{~cm} \times 50 \mathrm{~cm}$. Lahan diberi naungan berupa paranet dengan intensitas cahaya matahari $40 \%$ selama 4 minggu agar tanaman yang baru dipindahkan tidak mati.

Pemeliharaan tanaman dilakukan dengan penyulaman, penyiraman, penyiangan gulma serta pengendalian hama dan penyakit tanaman. Penyulaman dilakukan pada umur 1 MST dengan cara mengganti tanaman yang mati dengan tanaman baru yang umurnya relatif sama dan seragam.

Pemanenan secara destruktif yaitu mengambil seluruh bagian tanaman. Tanaman yang telah dipanen, dicuci kemudian dikeringanginkan terlebih dahulu selama beberapa menit agar kadar airnya berkurang. Bagian daun dan akar dipisah kemudian masing-masing ditimbang untuk memperoleh data bobot basah, indeks luas daun dan bobot kering tanaman.

Peubah vegetatif yang diamati setiap minggu antara lain diameter tajuk terlebar, panjang daun terpanjang, jumlah daun dihitung pada daun tempuyung yang sudah membuka secara penuh dan jumlah anakan. Bobot basah dan kering daun dan akar dilakukan pada umur 5, 8 dan 11 MST.

Laju tumbuh relatif (LTR) tanaman tempuyung dapat diketahui dari data bobot kering dan waktu. Laju tumbuh relatif ini menunjukkan peningkatan bobot kering dalam interval waktu. Cara menghitung laju tumbuh relatif (LTR) yaitu:

Laju tumbuh relatif $=\frac{\ln W 2-\ln W 1}{T 2-T 1}$

Keterangan: $\mathrm{W}_{1}=$ Bobot kering pada waktu $\mathrm{T}_{1}(\mathrm{~g})$, $\mathrm{W}_{2}=$ Bobot kering pada waktu $\mathrm{T}_{2}(\mathrm{~g})$, $\mathrm{T}_{1}=$ Waktu pengamatan awal (minggu), $\mathrm{T}_{2}=$ Waktu pengamatan akhir (minggu)

Perhitungan Indeks Luas Daun dilakukan pada setiap tanaman panen. Cara menghitung Indeks Luas Daun (ILD) yaitu:

ILD =

bobot kertas replika x luas kertas $20 \mathrm{~cm} \times 20 \mathrm{~cm}$ bobot kertas $20 \mathrm{~cm}$ x $20 \mathrm{~cm}$ $\times$ luas lahan

\section{HASIL DAN PEMBAHASAN}

\section{Kondisi Umum}

Suhu rata-rata harian tiap bulan berkisar antara 25.8-26.4 ${ }^{\circ} \mathrm{C}$ dengan rata-rata suhu bulanan selama percobaan yaitu $26.2{ }^{\circ} \mathrm{C}$.
Curah hujan harian tiap bulan berkisar antara 216-406 mm dengan rata-rata curah hujan bulanan selama percobaan yaitu $307.5 \mathrm{~mm}$. Intensitas penyinaran matahari tiap bulan berkisar antara 283-330 Cal cm-2 dengan rata rata intensitas penyinaran matahari selama percobaan yaitu $305.3 \mathrm{Cal} \mathrm{cm}^{-2}$.

Hama yang terdapat selama penelitian berlangsung adalah kutu daun dan belalang. Kutu daun mulai menyerang saat tanaman berumur 3 MST dan terdapat di bagian bawah daun. Beberapa tanaman tempuyung mengalami busuk pangkal batang yang terjadi pada 10 MST pada suhu rata-rata harian tiap bulan $23.7^{\circ} \mathrm{C}$ dan curah hujan rata-rata harian tiap bulan yaitu $399 \mathrm{~mm}$. Busuk pangkal batang disebabkan oleh cendawan Rhizoctonia solani.

Peubah vegetatif rata-rata memiliki nilai yang optimum pada umur 8 MST dan menurun pada umur 9 MST yang diikuti dengan masuknya fase generatif. Tanaman tempuyung mulai muncul bunga pada umur 8 MST setelah transplanting. Penelitian Wahyuningsih (2005) menunjukkan bahwa tanaman tempuyung mulai berbunga saat 35-60 hari setelah transplanting karena keragaman tanaman yang tinggi dan respon tanaman terhadap cekaman.

Hasil analisis tanah pada awal percobaan menunjukkan $\mathrm{pH}$ masam 4.9. Menurut Foragri (2011), tanaman tempuyung menyukai tempat yang memiliki $\mathrm{pH}$ basa. Kandungan N-Total tanah tergolong rendah hanya $0.13 \%$.

\section{Pengaruh Media Tanam terhadap Peubah Diameter Tajuk, Panjang Daun, Jumlah daun dan Jumlah Anakan}

Komposisi media tanam tidak menyebabkan perbedaan nyata pada peubah diameter tajuk, panjang daun, jumlah daun dan jumlah anakan. Pengaruh ketiga perlakuan (dengan kapur) juga tidak berbeda nyata dengan pembanding tanpa kapur (Tabel 1, 2, 3 dan 4).

Perlakuan penambahan pupuk kandang maupun arang sekam meskipun tidak nyata cenderung menyebabkan nilai peubah vegetatif tanaman lebih tinggi dibandingkan dengan media tanah dan kapur saja. Penelitian Husnan (2000) menunjukkan bahwa pemberian pupuk kandang sapi dengan dosis $0.5 \mathrm{~kg}$ per tanaman berpengaruh pada peningkatan peubah vegetatif tanaman tempuyung. Tanpa penambahan pupuk kandang dan arang sekam diduga menyebabkan kurang tersedianya hara tanaman. 
Perlakuan tanpa penambahan pupuk kandang dan arang sekam mencapai diameter tajuk maksimum pada umur 7 MST, sedangkan dengan penambahan pupuk kandang dan arang sekam serta pembanding tanpa kapur diameter tajuk maksimum tercapai pada umur 8 MST (Tabel 1). Hal ini menunjukkan bahwa pertumbuhan tempuyung tanpa penambahan pupuk kandang cenderung lebih terhambat dibandingkan dengan yang lain. Serupa dengan hasil penelitian Baskoro dan Santoso (2011) yang menyimpulkan pertumbuhan bibit binahong pada media yang ditambahkan bahan organik (kompos, pupuk kandang sapi pupuk kandang ayam) lebih baik (komponen bobot basah dan kering akar, batang, daun, dan total tanaman) dibandingkan tanpa perlakuan pupuk organik.

Penambahan pupuk kandang maupun arang sekam menyebabkan ukuran dan jumlah daun mencapai maksimum pada umur 8-9
MST sedangkan tanpa penambahan pupuk kandang menyebabkan kedua peubah tersebut mencapai nilai maksimum pada waktu lebih awal (Tabel 2 dan 3). Pupuk kandang dapat memperbaiki sifat fisik tanah (Hartatik dan Widowati 2009) dan karakteristik arang sekam yang bersifat poros menyebabkan aerasi dan drainase menjadi baik (Waryuningsih dan Darliah, 1994). Percobaan mengenai penambahan pupuk kandang dan arang sekam perlu dikaji lebih lanjut untuk melihat respon tanaman terhadap jenis dan dosis pupuk kandang serta arang sekam. Penambahan pupuk kandang dan tanpa penambahan pupuk kandang terjadi penurunan panjang daun pada umur \pm 9 MST (Tabel 2) sedangkan penurunan jumlah daun terjadi pada umur \pm 10 MST (Tabel 3). Jumlah daun menurun dapat disebabkan oleh gugurnya daun tua.

Tabel 1. Rata-rata diameter tajuk tanaman tempuyung

\begin{tabular}{cccccr}
\hline $\begin{array}{c}\text { Diameter } \\
\text { tajuk pada } \\
\text { minggu ke- }\end{array}$ & $\begin{array}{l}8 \mathrm{~kg} \\
\text { tanah+kapur }\end{array}$ & $\begin{array}{l}7.5 \mathrm{~kg} \\
\text { tanah+0.5 kg } \\
\text { pukan+kapur }\end{array}$ & $\begin{array}{l}\text { P kg tanah+0.5 kg } \\
\text { pukan+0.5 kg arang } \\
\text { sekam+kapur }\end{array}$ & $\begin{array}{l}\text { Pembanding } \\
\begin{array}{l}\text { kg tanah+0.5 } \\
\text { kg pukan+0.5 } \\
\text { kg arang sekam }\end{array}\end{array}$ & KK \\
\hline 1 & 12.29 & 12.22 & 11.56 & 11.72 & 7.27 \\
2 & 14.61 & 15.36 & 14.72 & 14.21 & 9.85 \\
3 & 19.32 & 20.50 & 20.11 & 17.61 & 9.03 \\
4 & 25.15 & 28.48 & 29.22 & 26.91 & 10.38 \\
5 & 27.68 & 31.07 & 32.19 & 29.33 & 10.55 \\
6 & 29.06 & 34.66 & 35.11 & 33.13 & 9.78 \\
7 & 29.54 & 35.62 & 35.39 & 34.56 & 9.91 \\
8 & 29.23 & 36.20 & 35.70 & 37.26 & 10.91 \\
9 & 28.77 & 35.89 & 35.67 & 35.43 & 10.81 \\
10 & 26.64 & 33.13 & 35.17 & 36.08 & 17.56 \\
11 & 27.74 & 35.08 & 35.38 & 22.95 & 21.21 \\
\hline
\end{tabular}

Tabel 2. Rata-rata panjang daun terpanjang tanaman tempuyung

\begin{tabular}{|c|c|c|c|c|c|}
\hline \multirow[b]{2}{*}{$\begin{array}{l}\text { Panjang } \\
\text { daun pada } \\
\text { minggu ke- }\end{array}$} & \multicolumn{3}{|c|}{ Perlakuan } & \multirow{2}{*}{\begin{tabular}{l}
\multicolumn{1}{c}{ Pembanding } \\
$7 \mathrm{~kg}$ tanah +0.5 \\
$\mathrm{~kg}$ pukan $+0.5 \mathrm{~kg}$ \\
arang sekam
\end{tabular}} & \multirow[b]{2}{*}{ KK } \\
\hline & $\begin{array}{l}8 \mathrm{~kg} \\
\text { tanah+kapur }\end{array}$ & $\begin{array}{l}7.5 \mathrm{~kg} \\
\text { tanah+0.5 kg } \\
\text { pukan+kapur }\end{array}$ & $\begin{array}{l}7 \mathrm{~kg} \text { tanah+0.5 kg } \\
\text { pukan+0.5 kg arang } \\
\text { sekam+kapur }\end{array}$ & & \\
\hline 1 & 7.61 & 7.84 & 7.47 & 7.55 & 6.41 \\
\hline 2 & 8.75 & 9.24 & 9.13 & 8.63 & 5.39 \\
\hline 3 & 11.89 & 11.98 & 12.59 & 11.18 & 8.37 \\
\hline 4 & 14.72 & 15.72 & 16.40 & 14.92 & 9.78 \\
\hline 5 & 15.52 & 16.44 & 17.15 & 16.21 & 10.39 \\
\hline 6 & 15.56 & 18.07 & 17.93 & 17.90 & 9.54 \\
\hline 7 & 15.55 & 18.95 & 18.54 & 18.05 & 9.84 \\
\hline 8 & 15.79 & 19.53 & 18.98 & 19.79 & 9.22 \\
\hline 9 & 15.63 & 18.98 & 19.01 & 18.94 & 10.43 \\
\hline 10 & 14.88 & 17.84 & 18.27 & 19.07 & 12.65 \\
\hline 11 & 15.15 & 17.90 & 17.86 & 11.74 & 16.95 \\
\hline
\end{tabular}


Tabel 3. Rata-rata jumlah daun tanaman tempuyung

\begin{tabular}{|c|c|c|c|c|c|}
\hline \multirow[b]{2}{*}{$\begin{array}{l}\text { Jumlah } \\
\text { daun pada } \\
\text { minggu ke- }\end{array}$} & \multicolumn{3}{|c|}{ Perlakuan } & \multirow{2}{*}{\begin{tabular}{l}
\multicolumn{1}{c}{ Pembanding } \\
$7 \mathrm{~kg}$ tanah+0.5 \\
$\mathrm{kg}$ pukan +0.5 \\
$\mathrm{~kg}$ arang sekam
\end{tabular}} & \multirow[b]{2}{*}{ KK } \\
\hline & $\begin{array}{l}8 \mathrm{~kg} \\
\text { tanah+kapur }\end{array}$ & $\begin{array}{l}7.5 \mathrm{~kg} \\
\text { tanah+0.5 kg } \\
\text { pukan+kapur }\end{array}$ & $\begin{array}{l}7 \mathrm{~kg} \text { tanah+0.5 kg } \\
\text { pukan+0.5 kg arang } \\
\text { sekam+kapur }\end{array}$ & & \\
\hline 1 & 2.3 & 2.3 & 2.3 & 2.1 & 11.34 \\
\hline 2 & 3.2 & 2.9 & 3.1 & 2.9 & 9.24 \\
\hline 3 & 4.5 & 4.8 & 4.8 & 4.3 & 9.63 \\
\hline 4 & 7.2 & 7.8 & 7.3 & 7.1 & 10.81 \\
\hline 5 & 8.1 & 9.4 & 8.7 & 8.5 & 12.76 \\
\hline 6 & 9.4 & 11.6 & 10.9 & 11.4 & 17.11 \\
\hline 7 & 9.8 & 12.0 & 15.7 & 12.6 & 22.82 \\
\hline 8 & 11.1 & 15.7 & 11.1 & 15.7 & 20.85 \\
\hline 9 & 11.2 & 17.4 & 15.0 & 16.2 & 23.14 \\
\hline 10 & 9.5 & 16.7 & 16.7 & 16.7 & 24.12 \\
\hline 11 & 11.5 & 15.8 & 17.7 & 18.6 & 24.30 \\
\hline
\end{tabular}

Tabel 4. Rata-rata jumlah anakan tanaman tempuyung

\begin{tabular}{ccccc}
\hline \multirow{3}{*}{$\begin{array}{l}\text { Jumlah } \\
\text { anakan pada } \\
\text { minggu ke- }\end{array}$} & $\begin{array}{l}\text { 8 kg } \\
\text { tanah+kapur }\end{array}$ & $\begin{array}{l}7.5 \mathrm{~kg} \\
\text { tanah+0.5 kg } \\
\text { pukan+kapur }\end{array}$ & $\begin{array}{l}\text { P kg tanah+0.5 kg } \\
\text { pukan+0.5 kg arang } \\
\text { sekam+kapur }\end{array}$ & $\begin{array}{l}\text { P kg tanah+0.5 kg } \\
\text { pukan+0.5 kg } \\
\text { arang sekam }\end{array}$ \\
\hline 3 & 0.3 & 0.7 & 0.7 & 0.7 \\
4 & 0.3 & 0.7 & 0.7 & 0.8 \\
5 & 0.3 & 0.8 & 1.0 & 0.8 \\
6 & 0.3 & 0.9 & 1.0 & 1.3 \\
7 & 1.0 & 0.9 & 1.0 & 1.3 \\
8 & 1.3 & 1.4 & 1.1 & 1.4 \\
9 & 0.3 & 1.4 & 1.9 & 1.2 \\
10 & 1.0 & 1.5 & 1.0 & 1.2 \\
\hline
\end{tabular}

Secara umum terjadi pembentukan anakan yang lebih intensif pada umur 7 atau 8 MST (Tabel 4). Data jumlah anakan ini tidak dianalisis secara statistik karena keragaman pada setiap ulangan sangat tinggi. Keempat peubah di atas menunjukkan keterkaitan bahwa pertumbuhan vegetatif maksimum tercapai pada \pm 7-8 MST yang diikuti dengan pembentukan anakan yang lebih intensif. Penurunan pertumbuhan vegetatif dapat disebabkan oleh masuknya fase generatif yang ditandai dengan munculnya bunga.

\section{Pengaruh Media Tanam terhadap Peubah Bobot Basah dan Kering Daun dan Akar}

Komposisi media tanam tidak menyebabkan perbedaan nyata pada peubah bobot basah dan kering daun, dan bobot kering akar tanaman. Pengaruh ketiga perlakuan (dengan kapur) juga tidak berbeda nyata dengan pembanding tanpa kapur (Tabel 5 dan 6), tetapi berbeda nyata lebih kecil dengan pembanding tanpa kapur pada peubah bobot basah akar dengan perlakuan penambahan pupuk kandang dan arang sekam pada umur 5 MST (Tabel 6).

Bobot basah dan kering daun dan akar diukur pada umur 5, 8 dan 11 MST. Rata-rata bobot basah dan kering daun optimal pada umur 8 MST (Tabel 5) sedangkan bobot basah dan kering akar meningkat di setiap selang tiga minggu (Tabel 6). Bobot basah dan kering daun dan akar tanaman dengan penambahan pupuk kandang maupun arang sekam cenderung lebih baik. 
J. Hort. Indonesia 5(1):47-55. April 2014.

Tabel 5. Rata-rata bobot basah dan kering daun tanaman tempuyung

\begin{tabular}{|c|c|c|c|c|c|}
\hline \multirow[b]{2}{*}{$\begin{array}{c}\text { Umur } \\
\text { tanaman } \\
\text { (MST) }\end{array}$} & \multicolumn{3}{|c|}{ Perlakuan } & \multirow{2}{*}{\begin{tabular}{l}
\multicolumn{1}{c}{ Pembanding } \\
$7 \mathrm{~kg}$ tanah+0.5 kg \\
pukan+0.5 kg arang \\
sekam
\end{tabular}} & \multirow[b]{2}{*}{ KK } \\
\hline & $\begin{array}{l}8 \mathrm{~kg} \\
\text { tanah+kapur }\end{array}$ & $\begin{array}{l}7.5 \mathrm{~kg} \text { tanah+0.5 } \\
\text { kg pukan+kapur }\end{array}$ & $\begin{array}{l}7 \mathrm{~kg} \text { tanah+0.5 kg } \\
\text { pukan+0.5 kg arang } \\
\text { sekam+kapur }\end{array}$ & & \\
\hline \multicolumn{6}{|c|}{.................Bobot basah daun $(\mathrm{g}) \ldots \ldots \ldots \ldots \ldots \ldots$} \\
\hline $5 \mathrm{MST}$ & 5.28 & 6.02 & 5.00 & 6.16 & 11.33 \\
\hline $8 \mathrm{MST}$ & 37.59 & 27.53 & 38.24 & 42.82 & 14.15 \\
\hline $11 \mathrm{MST}$ & 17.67 & 48.10 & 34.53 & 37.75 & 11.73 \\
\hline \multicolumn{6}{|c|}{ Bobot kering daun $(\mathrm{g}) \ldots \ldots \ldots \ldots \ldots \ldots$} \\
\hline $5 \mathrm{MST}$ & 0.64 & 0.76 & 0.64 & 0.67 & 5.65 \\
\hline $8 \mathrm{MST}$ & 7.25 & 3.65 & 4.31 & 5.01 & 21.17 \\
\hline $11 \mathrm{MST}$ & 2.11 & 4.90 & 3.76 & 4.15 & 13.00 \\
\hline
\end{tabular}

Keterangan: Analisis statistika ditransformasi $(\mathrm{x}+1 / 2)^{1 / 2}$.

Tabel 6. Rata-rata bobot basah dan kering akar tanaman tempuyung

\begin{tabular}{|c|c|c|c|c|c|}
\hline \multirow{2}{*}{$\begin{array}{l}\text { Umur } \\
\text { tanaman } \\
\text { (MST) }\end{array}$} & \multicolumn{3}{|c|}{ Perlakuan } & \multirow{2}{*}{\begin{tabular}{l}
\multicolumn{1}{c}{ Pembanding } \\
$7 \mathrm{~kg}$ tanah $+0.5 \mathrm{~kg}$ \\
pukan $+0.5 \mathrm{~kg}$ \\
arang sekam
\end{tabular}} & \multirow[b]{2}{*}{ KK } \\
\hline & $\begin{array}{l}8 \mathrm{~kg} \\
\text { tanah+kapur }\end{array}$ & $\begin{array}{l}7.5 \mathrm{~kg} \text { tanah+0.5 } \\
\mathrm{kg} \text { pukan+kapur }\end{array}$ & $\begin{array}{l}7 \mathrm{~kg} \text { tanah+0.5 kg } \\
\text { pukan+0.5 kg arang } \\
\text { sekam+kapur }\end{array}$ & & \\
\hline & \multicolumn{5}{|c|}{$\ldots \ldots \ldots \ldots \ldots \ldots \ldots$ Bobot basah akar $(\mathrm{g}) \ldots \ldots \ldots \ldots \ldots \ldots \ldots$} \\
\hline $5 \mathrm{MST}$ & 1.79 & 2.73 & 1.53 & 2.44 & 6.10 \\
\hline $8 \mathrm{MST}$ & 27.92 & 25.09 & 30.20 & 33.87 & 19.21 \\
\hline $11 \mathrm{MST}$ & 27.46 & 56.28 & 55.74 & 54.57 & 10.37 \\
\hline \multicolumn{6}{|c|}{ 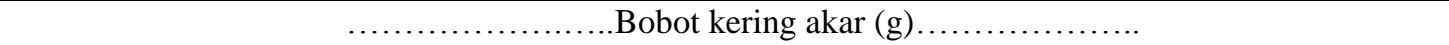 } \\
\hline 5 MST & 0.28 & 0.42 & 0.33 & 0.36 & 4.69 \\
\hline $8 \mathrm{MST}$ & 4.32 & 5.68 & 6.60 & 6.80 & 13.58 \\
\hline $11 \mathrm{MST}$ & 6.34 & 13.34 & 10.82 & 9.93 & 11.65 \\
\hline
\end{tabular}

Rata-rata bobot basah daun berkisar 34$42 \mathrm{~g}$ dan bobot kering daun berkisar 3-5 g pada umur 8 dan 11 MST (Tabel 5). Rata-rata bobot basah akar berkisar 25-56 g dan bobot kering akar berkisar 4-13 g (Tabel 6). Berbeda halnya dengan penelitian Wahyuningsih (2005), bobot basah daun berkisar 120-125 g, bobot kering daun 14-15 g, bobot basah akar berkisar 102$109 \mathrm{~g}$ dan bobot kering akar 30-32 g. Hal ini diduga karena perbedaan cara panen yaitu dengan adanya pemangkasan tangkai bunga. Percobaan yang dilakukan saat ini tidak membiarkan terbentuknya tangkai bunga, namun memanen ketika mulai terbentuk bakal tangkai bunga. Oleh karena itu, bobot tanaman lebih rendah dibandingkan dengan hasil penelitian Wahyuningsih (2005).

\section{Laju tumbuh relatif}

Komposisi media tanam tidak menyebabkan perbedaan nyata pada peubah laju tumbuh relatif. Pengaruh ketiga perlakuan (dengan kapur) juga tidak berbeda nyata dengan pembanding tanpa kapur (Tabel 7). Laju tumbuh relatif (LTR) daun dan akar tempuyung menurun pada umur 8-11 MST. Hal ini disebabkan oleh gugurnya daun tua. Perlakuan penambahan pupuk kandang dan arang sekam memiliki LTR daun tertinggi pada umur 5-8 MST sedangkan pembanding tanpa kapur memiliki LTR akar tertinggi pada umur 5-8 MST dan 811 MST (Tabel 7). Hal ini diduga karena karakteristik arang sekam yang porus sehingga memudahkan akar untuk menembus tanah. 
Tabel 7. Laju tumbuh relatif tanaman tempuyung

\begin{tabular}{|c|c|c|c|c|c|}
\hline \multirow[b]{2}{*}{$\begin{array}{l}\text { Umur } \\
\text { tanaman } \\
\text { (MST) }\end{array}$} & \multicolumn{3}{|c|}{ Perlakuan } & \multirow{2}{*}{$\begin{array}{l}\text { Pembanding } \\
7 \mathrm{~kg} \text { tanah }+0.5 \\
\mathrm{~kg} \text { pukan }+0.5 \\
\mathrm{~kg} \text { arang sekam }\end{array}$} & \multirow[b]{2}{*}{ KK } \\
\hline & $\begin{array}{l}8 \mathrm{~kg} \\
\text { tanah+kapur }\end{array}$ & $\begin{array}{l}7.5 \mathrm{~kg} \\
\text { tanah+0.5 kg } \\
\text { pukan+kapur }\end{array}$ & $\begin{array}{l}7 \mathrm{~kg} \text { tanah+0.5 kg } \\
\text { pukan+0.5 kg arang } \\
\text { sekam+kapur }\end{array}$ & & \\
\hline & \multicolumn{5}{|c|}{..Laju tumbuh relatif daun $\left(\mathrm{g}_{\text {hari }}{ }^{-1}\right)$} \\
\hline 5-8 MST & 1.34 & 1.56 & 1.92 & 1.33 & 8.25 \\
\hline 8-11 MST & -0.17 & 0.09 & -0.06 & 0.11 & 30.97 \\
\hline \multicolumn{6}{|c|}{$\ldots \ldots \ldots \ldots \ldots \ldots$ Laju tumbuh relatif akar $\left(\mathrm{g} \mathrm{cm}^{-2}\right.$ hari $\left.^{-1}\right) \ldots \ldots \ldots \ldots \ldots \ldots$} \\
\hline 5-8 MST & 0.84 & 0.86 & 1.01 & 1.04 & 3.70 \\
\hline 8-11 MST & 0.33 & 0.28 & 0.17 & 0.34 & 20.65 \\
\hline
\end{tabular}

Keterangan: Analisis statistika ditransformasi $(x+1 / 2)^{1 / 2}$.

\section{Kadar Air Daun dan Akar Tanaman}

Komposisi media tanam tidak menyebabkan perbedaan nyata pada peubah kadar air daun dan akar tanaman. Pengaruh ketiga perlakuan (dengan kapur) juga tidak berbeda nyata dengan pembanding tanpa kapur tetapi berbeda nyata lebih kecil dengan pembanding tanpa kapur pada peubah kadar air akar dengan perlakuan penambahan pupuk kandang pada umur 11 MST (Tabel 8).

Kadar air daun berkisar $87-89 \%$ sedangkan kadar air akar berkisar $76-81 \%$.
Siemonsa dan Pileuk (1994) menyatakan bahwa kadar air daun sebesar $88 \%$. Persentase kadar air yang tinggi menunjukkan daun tidak dapat disimpan lama dalam keadaan segar sehingga langsung dikeringkan agar daun tidak busuk dan rusak. Kadar air daun tertinggi berbedabeda di selang tiga minggu sedangkan kadar air akar pembanding tanpa kapur memiliki nilai tertinggi pada umur 5 dan 11 MST. Perlakuan tanpa penambahan pupuk kandang dan arang sekam memiliki kadar air akar tertinggi pada umur 8 MST (Tabel 8).

Tabel 8. Rata-rata kadar air daun dan akar tanaman tempuyung

\begin{tabular}{|c|c|c|c|c|c|}
\hline \multirow[b]{2}{*}{$\begin{array}{l}\text { Umur } \\
\text { tanaman } \\
\text { (MST) }\end{array}$} & \multicolumn{3}{|c|}{ Perlakuan } & \multirow{2}{*}{$\begin{array}{l}\text { Pembanding } \\
7 \mathrm{~kg} \text { tanah+0.5 } \\
\mathrm{kg} \text { pukan+0.5 } \\
\mathrm{kg} \text { arang sekam }\end{array}$} & \multirow[b]{2}{*}{ KK } \\
\hline & $\begin{array}{l}8 \mathrm{~kg} \\
\text { tanah+kapur }\end{array}$ & $\begin{array}{l}7.5 \mathrm{~kg} \text { tanah+0.5 } \\
\text { kg pukan+kapur }\end{array}$ & $\begin{array}{l}7 \mathrm{~kg} \text { tanah+0.5 kg } \\
\text { pukan+0.5 kg arang } \\
\text { sekam+kapur }\end{array}$ & & \\
\hline \multicolumn{6}{|c|}{..Kadar air daun $(\%) \ldots \ldots \ldots \ldots \ldots \ldots \ldots \ldots \ldots \ldots \ldots \ldots$} \\
\hline $5 \mathrm{MST}$ & 87.70 & 87.45 & 87.21 & 89.02 & 1.33 \\
\hline $8 \mathrm{MST}$ & 82.84 & 86.79 & 88.66 & 88.32 & 2.70 \\
\hline $11 \mathrm{MST}$ & 88.07 & 89.47 & 89.00 & 89.16 & 1.95 \\
\hline \multicolumn{6}{|c|}{ 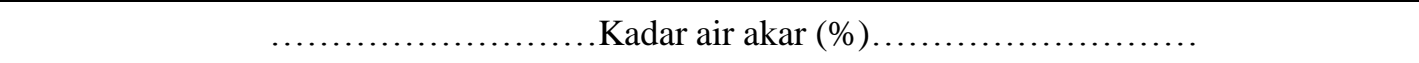 } \\
\hline $5 \mathrm{MST}$ & 83.62 & 84.52 & 78.74 & 85.21 & 3.37 \\
\hline $8 \mathrm{MST}$ & 80.73 & 76.38 & 78.44 & 79.92 & 3.78 \\
\hline 11 MST & 76.89 & 76.19 & 81.20 & 81.98 & 2.19 \\
\hline
\end{tabular}

Keterangan: *** menunjukkan nilai berbeda nyata pada t-dunnett dibandingkan dengan kontrol. 


\section{Indeks Luas Daun}

Komposisi media tanam tidak menyebabkan perbedaan nyata pada peubah indeks luas daun (ILD). Pengaruh ketiga perlakuan (dengan kapur) juga tidak berbeda nyata dengan pembanding tanpa kapur.

Tabel 9. Rata-rata indeks luas daun tanaman tempuyung

\begin{tabular}{|c|c|c|c|c|c|}
\hline \multirow[b]{2}{*}{$\begin{array}{l}\text { Umur } \\
\text { tanaman } \\
\text { (MST) }\end{array}$} & \multicolumn{3}{|c|}{ Perlakuan } & \multirow{2}{*}{\begin{tabular}{l}
\multicolumn{1}{c}{ Pembanding } \\
$7 \mathrm{~kg}$ tanah +0.5 \\
$\mathrm{~kg}$ pukan $+0.5 \mathrm{~kg}$ \\
arang sekam
\end{tabular}} & \multirow[b]{2}{*}{ KK } \\
\hline & $\begin{array}{l}8 \mathrm{~kg} \\
\text { tanah+kapur }\end{array}$ & $\begin{array}{l}7.5 \mathrm{~kg} \\
\text { tanah+0.5 kg } \\
\text { pukan+kapur }\end{array}$ & $\begin{array}{l}7 \mathrm{~kg} \text { tanah+0.5 } \mathrm{kg} \\
\text { pukan+0.5 kg arang } \\
\text { sekam+kapur }\end{array}$ & & \\
\hline & \multicolumn{5}{|c|}{ Indeks luas daun ${ }^{\mathrm{t}}$. } \\
\hline $8 \mathrm{MST}$ & 0.32 & 0.26 & 0.31 & 0.40 & 2.74 \\
\hline $9 \mathrm{MST}$ & 0.24 & 0.08 & 0.29 & 0.26 & 2.16 \\
\hline $10 \mathrm{MST}$ & 0.22 & 0.28 & 0.36 & 0.36 & 7.52 \\
\hline $11 \mathrm{MST}$ & 0.16 & 0.18 & 0.25 & 0.34 & 4.16 \\
\hline
\end{tabular}

Keterangan: Analisis statistika ditransformasi $(\mathrm{x}+1 / 2)^{1 / 2} \cdot{ }^{1}$ menunjukkan bahwa tidak diuji secara statistik karena hanya 1 ulangan yang diuji dengan pembanding.

Pembanding tanpa kapur memiliki nilai ILD tertinggi pada umur 8, 10, dan 11 MST. Perlakuan penambahan pupuk kandang dan arang sekam memiliki nilai ILD tertinggi pada umur 9 MST (Tabel 9).

\section{KESIMPULAN}

Komposisi media tanam tidak mempengaruhi peubah vegetatif dan komponen hasil tanaman tempuyung secara nyata namun ada kecenderungan bahwa penambahan pupuk kandang sapi maupun arang sekam menyebabkan pertumbuhan tanaman yang lebih baik. Bobot basah akar pada umur 5 MST dengan penambahan pupuk kandang nyata lebih kecil dibandingkan dengan perlakuan tanpa kapur.

\section{DAFTAR PUSTAKA}

Baskoro, D., B.S. Purwoko. 2011. Pengaruh bahan perbanyakan tanaman dan jenis pupuk organik terhadap pertumbuhan tanaman binahong (Anredera cordifolia (Ten.) Steenis). J. Hort. Indonesia. 2(1): 6-13.

Chairani. 2006. Pengaruh fosfor dan pupuk kandang kotoran sapi terhadap sifat kimia tanah dan pertumbuhan padi (Oryza sativa) pada lahan sawah tadah hujan di Langkat, Sumatera Utara Jurnal Penelitian Pertanian. 25(1): 8-14.

Dalimartha, S. 2005. Tanaman Obat di Lingkungan Sekitar. Cet. 1. Puspa Swara. Jakarta.

Djauhariya, E., Hernani. 2004. Gulma Berkhasiat Obat. Cet. 1. Penebar Swadaya. Jakarta.

Foragri. 2011. Budi daya tempuyung [Internet]. Waktu unduh https://foragri.wordpress. com/2011/12/20/budi-daya-tempuyung. [9 Maret 2012].

Hadid, A., S. Laude. 2007. Pengaruh konsentrasi pupuk organik cair lengkap dan dosis pupuk kandang ayam terhadap pertumbuhan dan hasil tanaman bawang merah. Jurnal Agroland. 14(4): 260-264.

Harahap, K.A. 2005. Pengaruh pupuk terhadap pertumbuhan jagung yang ditanam di antara tanaman cendana (Santalum album L.). Jurnal Ilmu-ilmu Pertanian Agroland. 12(1): $1-6$.

Hartatik, W., L.R. Widowati. 2009. Pupuk kandang. http://balittanah.litbang. pertanian.go.id/ind/dokumentasi/buku/b uku\%20pupuk\%20hayatipupuk\%20orga nik/04pukan_wiwik.pdf [18 Maret 2012]. 
Husnan. 2000. Multiplikasi dan pengakaran in vitro tempuyung (Sonchus arvensis L.) serta pertumbuhan bibit pasca aklimatisasi Skripsi. Jurusan Budi Daya Pertanian, Fakultas Pertanian, Institut Pertanian Bogor. Bogor.

Hernani, R., Nudjanah. 2009. Aspek pengeringan dalam mempertahankan kandungan metabolit sekunder pada tanaman obat. Perkembangan Teknologi TRO. 21(2): 33-39.

Muhammad, H., M. Januwati, M. Iskandar. 1993. Pengaruh jarak tanam terhadap produksi daun tempuyung. Warta Tanaman Obat Indonesia. 2(3): 13-14.

Saleh, I. 2010. Pengaruh metode pemupukan dan kombinasi komposisi media tanam dengan pengapuran terhadap pertumbuhan cabe jawa (Piper retrofractum Vahl.). Skripsi. Program Studi Agronomi dan Hortikultura, Fakultas Pertanian, Institut Pertanian Bogor. Bogor.

Siemonsma, Pileuk. 1994. Di dalam: Husnan. Multiplikasi dan pengakaran in vitro tempuyung (Sonchus arvensis L.) serta pertumbuhan bibit pasca aklimatisasi. Skripsi. Bogor, Indonesia. Departemen Agronomi dan Hortikultura, Fakultas Pertanian, Institut Pertanian Bogor, hlm 17. Bogor.

Siswanto, U., E.I. Sukarjo, Risnaily. 2004. Respon tanaman tempuyung (Sonchus arvensis L.) pada berbagai takaran dan aplikasi vermikompos. Jurnal Ilmu-ilmu Pertanian. 6(2): 83-90.

Wahyuningsih, A.P.S. 2005. Pengaruh kombinasi aplikasi pupuk $\mathrm{N}$ dan waktu pemangkasan tangkai bunga terhadap pertumbuhan dan produksi tanaman tempuyung (Sonchus arvensis L.). Skripsi. Program Studi Agronomi dan Hortikultura, Fakultas Pertanian, Institut Pertanian Bogor. Bogor.

Wuryaningsih, Darliah. 1994. Di dalam: Safitry M.R. Pengaruh Media Tanam Organik terhadap Pertumbuhan dan Produksi Buncis Tegak (Phaseolus vulgaris L.) [skripsi]; Bogor, Indonesia. Departemen Agronomi dan Hortikultura, Fakultas Pertanian, Institut Pertanian Bogor, hlm 21. Bogor. 